Portland State University

PDXScholar

9-8-1971

\title{
Ames Trapezoid Illusion: A New Model
}

Daniel Robert Kelly

Portland State University

Follow this and additional works at: https://pdxscholar.library.pdx.edu/open_access_etds

Part of the Cognition and Perception Commons

Let us know how access to this document benefits you.

\section{Recommended Citation}

Kelly, Daniel Robert, "Ames Trapezoid Illusion: A New Model" (1971). Dissertations and Theses. Paper 1519.

https://doi.org/10.15760/etd.1518

This Thesis is brought to you for free and open access. It has been accepted for inclusion in Dissertations and Theses by an authorized administrator of PDXScholar. Please contact us if we can make this document more accessible: pdxscholar@pdx.edu. 
AN ABSPAOT OF THE THEJS OF Janda Pobor kelly for the

Mater of Aris in Prohiog presented Seperiter 8, 1571.

Mithe: Anes Trapezold Mrusion; A New Mocied.

AFUROTED SY MLMEFPS OF THE THFSTS COMMTTEE:
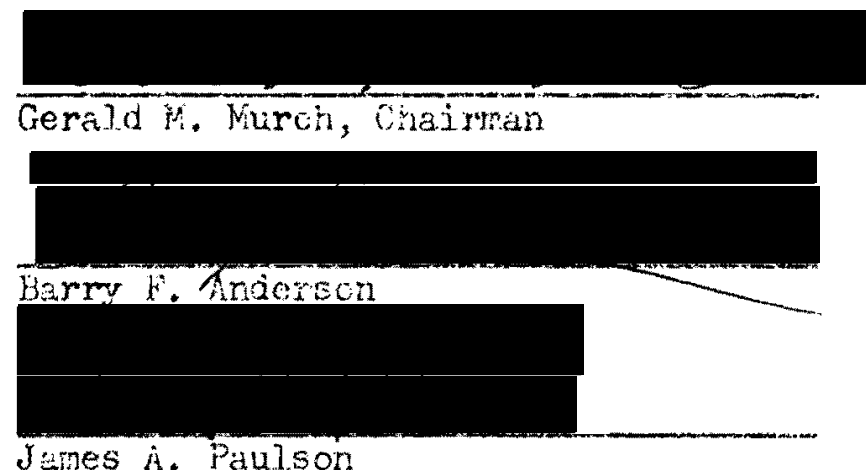

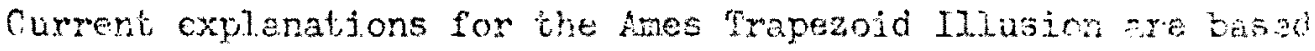
upon the absence of cues; the illusior is sad to uocur at chario. A review of resent literioure thomed that: (a) the iliusion viries in frogueney es a fucticn of terget shape (b) that she comintut oue

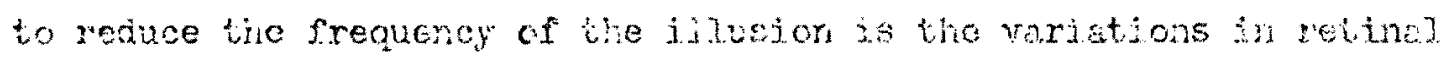
height. Based upon the dominanes of this aus a new noled wes prosentod,

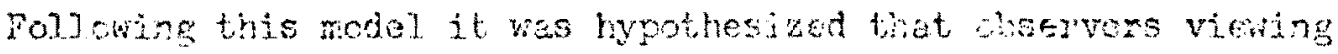
partiaj rotation when the target produces the reatect differace

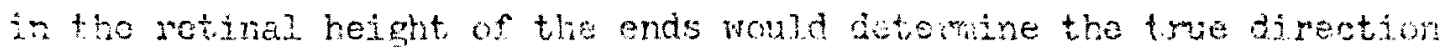

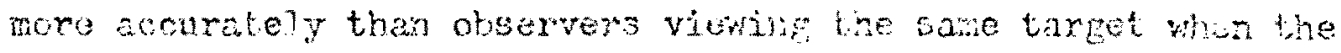

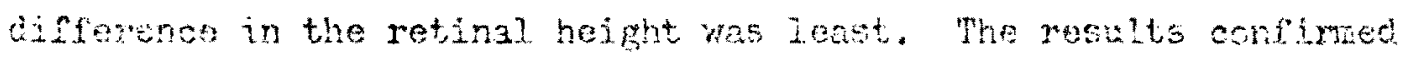
the inpothesis. 


\section{AMES TRAPEZOID ITIUSION:}

A NEW MDDET,

by

Daniel R. Kelly

A thesis submitied in pantial forfillment of the requirements for the degree of

MASTER OF SCIENCE

in

PSYCHOLOGY

Portland State University

1971 
TO THE OFFIC: OF GRADUATE SIUDIPS:

The menbers of the Comittoe approve the thesis of Daniel Robert Keily presented Suptember 8, 1971.

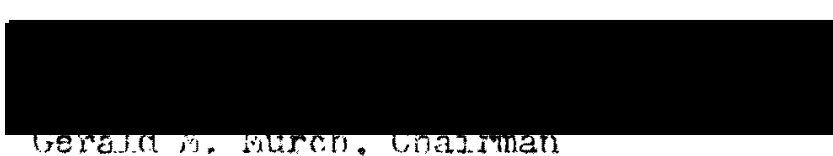

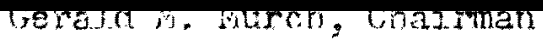
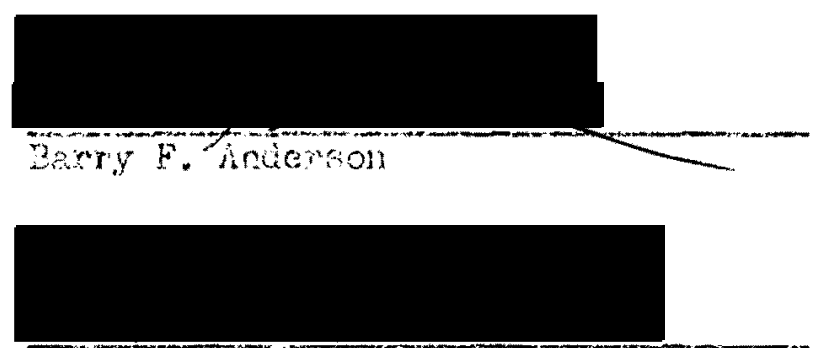

Janes A. Paulon

APROTHO:

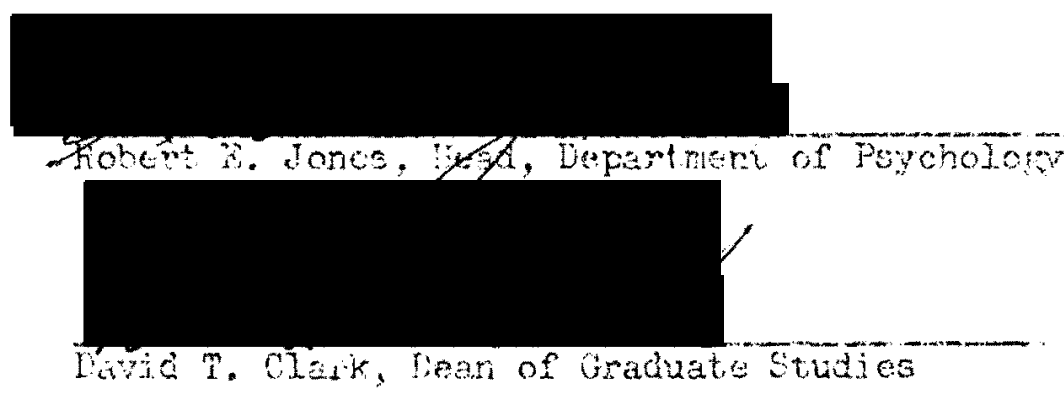

Septorton 8,1971 
TABLE OF CONITERS

PAGE

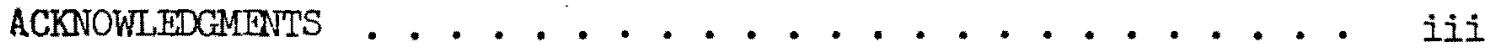

LIST OF TABLES ...................... . . v

IIST OF FTGURES . . . . . . . . . . . . . . . . vi

INTRODUCTION .................................... I

I RECENT RESEARCH ON CUES . . . . . . . . . . 1

II AN ALTERNATIVE MODEL ............... 17

III HYPONHESIS TEST . . . . . . . . . . . 14

METHOD . . . . . . . . . . . . . . . 15

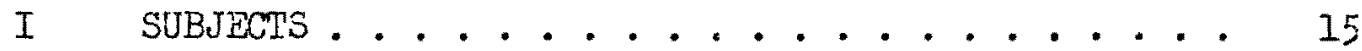

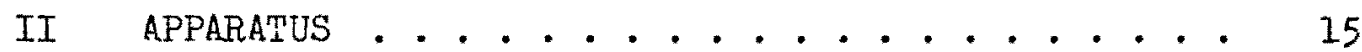

III PROCEDURE .................... I7

PESULTS . . . . . . . . . . . . . 18

DISCUSSION . . . . . . . . . . . . . 20 20

REFRENCES . . . . . . . . . . . . . . . . 21

APPTIDIX .................... . . 23

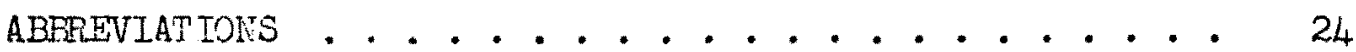




\section{ACKNOWLEDGMENTS}

I would like to thank first and most appreciatively Gerry Murch. Without his friendship, diligence and guidance I probably never would have begun this paper. However, once I did get started, he and the other members of my committee, Barry Anderson and Jim Paulson, worked far beyond the call of duty. Their thoughtful criticism is also much appreciated. Before the paper was finished I involved practically everybody in the department. Faculty members, graduate students and department secretaries all added their time and efforts. Now that it is through, what else can I say but, thanks!

This investigation was supported by Biomedicel Sciences Support. Grant FR-7128 from the General Research Support Eranch, Division of Research Resources, Bureau of Health Professions Education and Marnpower Training, National Institutes of Health. 
LIST OF TABLES

TABLE

PAGE

I Means and Standard Deviations of Seconds Correct and Total Seconds in Directional Judgments. . . I9 


\section{LIST OF FIGURPS}

FIGURE

PAGE

I Overhead View Depicting Polar Projection..... 4

II Proximal Size as a Function of Distal Position. . 5

III ParalleI Projections from the Circular Path . . . 9

IV Dimensions of the Target .......... I6 


\section{INTRODUCTION}

Rotation of a trapezoidal figure on a vertical axis midway between the parallel sides frequently appears as oscillation. This phenomenon

was first explained by Ames (1951) in terms of assumptions acquired from prior experience. He postulated that since the figure was made to resemble a window, observers were set to assume that the figure was rectangular. However, subsequent research has revealed that the illusion occurs with a wide variety of nonrectilinear shapes (Cross, 1969). Consequently Day and Power (1965) have proposed a general theory based upon the absence of cues to either true orientation or true direction. A judgment of motion direction was said to be governed by chance factors.

This paper reviews recent research which shows that cues are available to determine direction of rotation. In light of this research a new model is presented and tested experimentally. It is the position of this paper that the new model can account for the perception of rotation in terms of distinctive features inherent in the proximal transformations of the stimulus airay.

\section{RECENT RESEARCH ON CUES}

The theory of Day and Power is based upon the absence of cues which are distinctive to direction of rotation. Therefore, since all symmetrical shapes should have the same absence of cues, their theory cannot predict differences in the frequency of apparent reversals (AR) Gue to shape. It seems well agreed, however, that different shapes 
have different frequencies of AR (Conestarri, 1956; Mullholland, 1956; Pastore, 1952). It has also been shown that differences in shape affect the range of $A R$ (RAR), i.e., the arc within which AR occurs. Furthermore, RAR seems to be inversely related to the frequency of AR. Specifically, increases in the width (W) of a figure result in increases in RAR and decreases in AR (Epstein, Johanssan and Burjesson, 1968; Freeman and Fasnak, 1968). Increases in the height (H) result in decreases in RAR and increases in AR (Epstein, et al, 1968). In addition, increases in the difference of $\mathrm{H}$ of the vertical sides ( $\mathrm{H}-\mathrm{H}$ ) of a trapezoidal figure result in a decrease in RAF and an increase in AR (Freeman and Pasnak, 1968). Therefore, since differences in dimension alter the illusion, any theory which attempts to account for the oscillation phenomenon must consider the shape varjable (Burham and Ono, 1969).

Hershberger (1967) has show in a theoretical analysis that the theory of Day and Powers applies to parallel but not polar projections. This distinction between parallel and polar projection is not absolute, but varies as a function of distance. When the distance between an object and the observer (ㅇ) is infinite the rays of projection are parallel (parallel projection). When the distance is finite the rays from the polar edges of a figure converge upon the eye (polar projection). Hershberger's analysis shows that, in parallel projection, the transformations of the retinal image are identical for clockwise (CW) and counterclockwise (CCW) rotation. In polar projection, however, elements of the retinal iransformations are distinctive to each direction. Furthermore, the magnitude of these distinctive elements varies inversely 
with distance; as the distance is increased the availability of the elements as cues is decreased. Consequently, the theory of Day and Power can only apply to the exceptional case of parallel projection or a projection so nearly parallel that directional cues are below threshold. Further research on the definition of these cues and their limits is presented below.

MacRae and Fower (1969) have made a detailed theoretical analysis of differential angular velocity. Thej observed that the maximum horizontal visual angle or maximum $W$ for a one-sided, flag-like figure occurs not when a figure is at the frontoparallel plane (face on), but when the eye's line of regard is tangent to the circular path (see Figure 1). Consider, for example, the two graphs in Figure 2. In both graphs, the $\mathrm{x}$ axis represents the position in distel rotation, as shown in Figure 1; and the $y$ axis represents proximal $W$. If the speed of rotation is held constant, the guaphs show that it will take longer for a flag-like figure to travel from right maximum $W$ to left maximum $W$ along the distant quadrants than along the near quadrants. Therefore, in CW rotation, $W$ decreases for a shorter time than it increases; and, in CCW rotation, $W$ increases for a shorter time than it decreases. With a two-sided figure the relative rates of increase and decrease may be simultaneously compared. The near end changes faster than the far end. Hershberger and Urban (1970b) have isolated other potentially effective polar $W$ cues. The order in which points along the horizontal dimension reach their proximally maximum $W$ is different for the two directions. Let us examine, for example, the smaller circular path to the right of the axis in Figure 1. If a target is rotated CCW from 


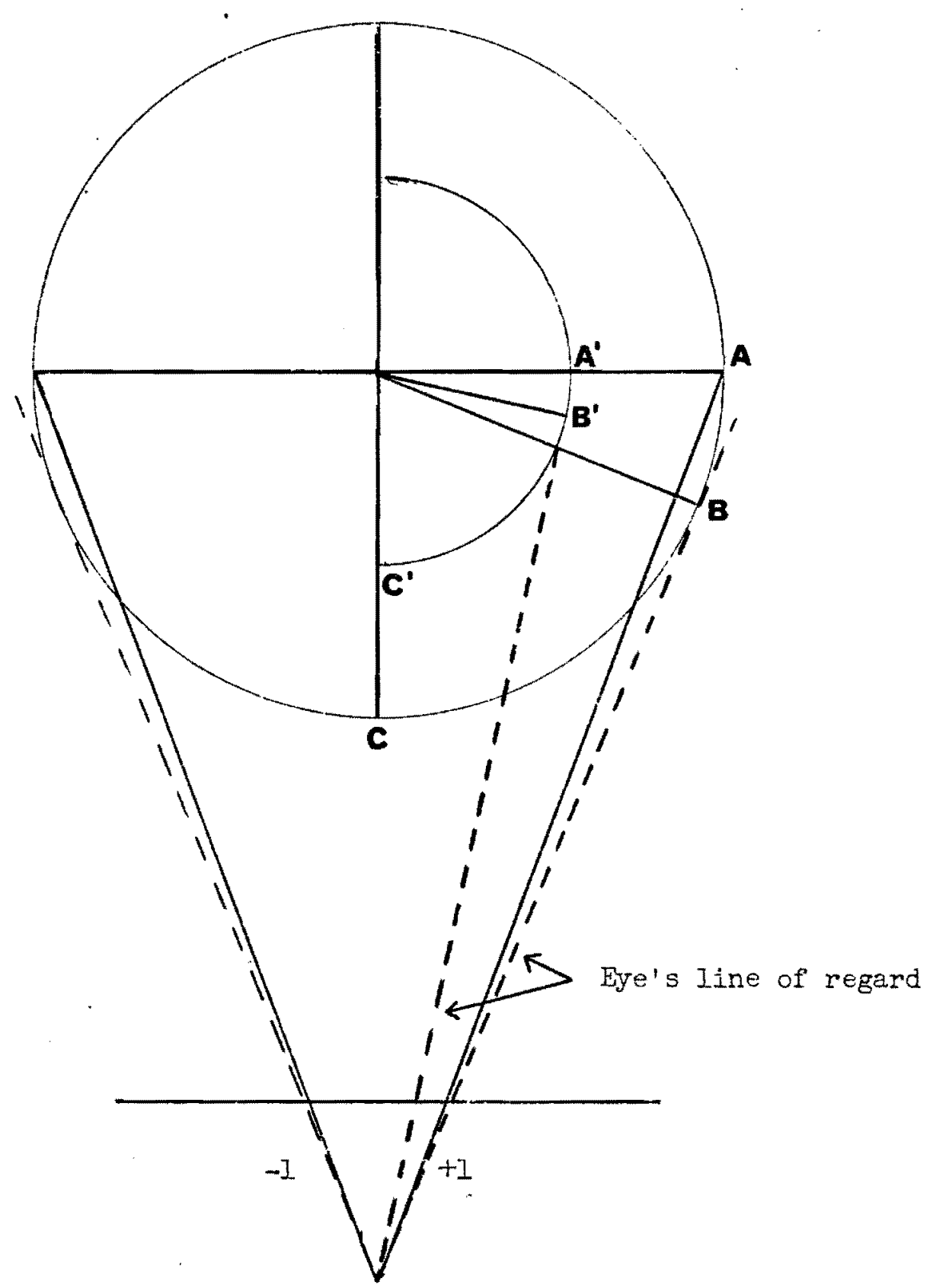

Figure 1. Overhead view depicting polar projection. 


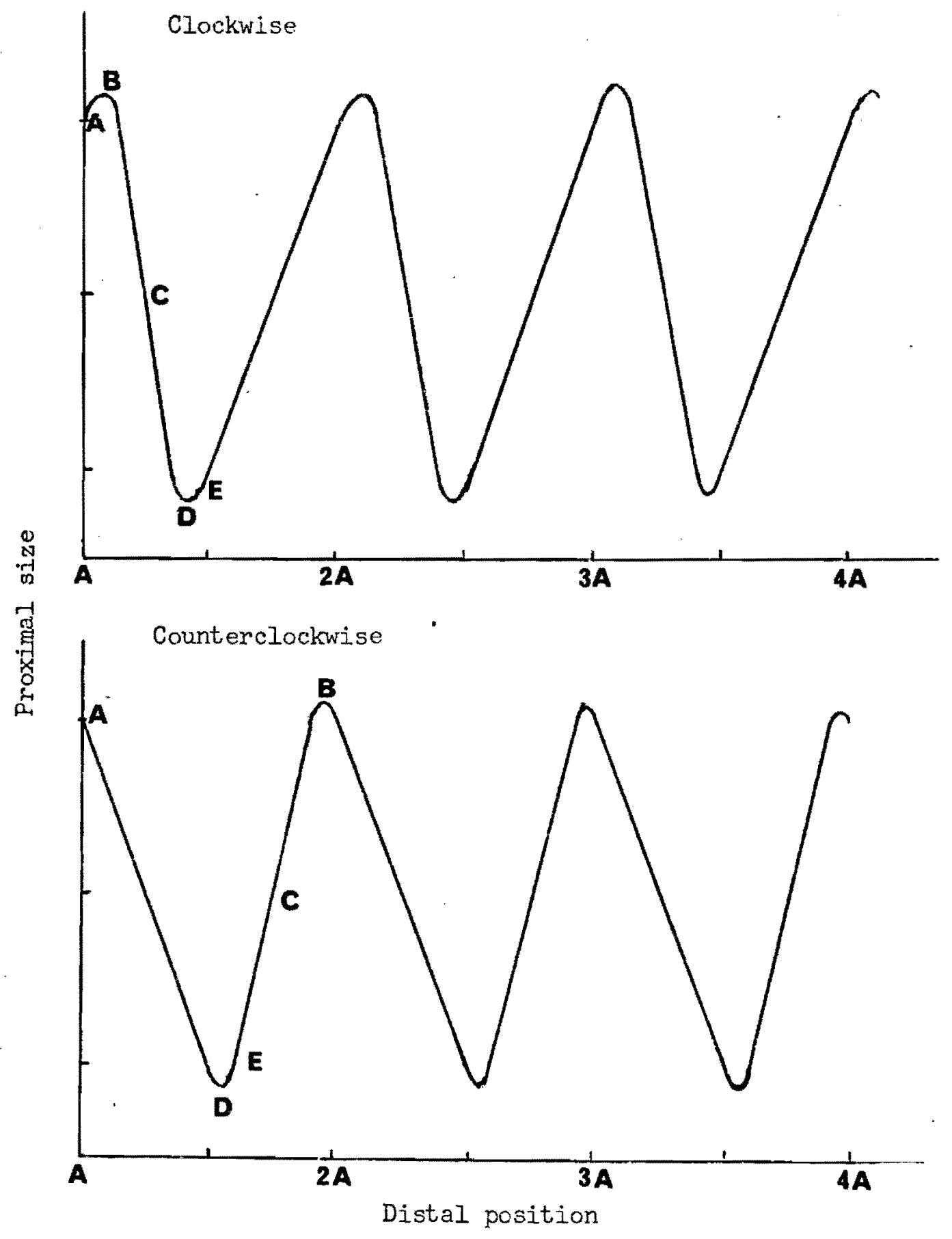

Figure 2. Proximal size as a function of distal position, in clockwise (CW) and counterclockwise (CCW) roto. 
sagittal then the outermost points on the right will reach the proximal size limits first. If a target is rotated CW from sagittal, the opposite is true. Thus, an $\underline{0}$ may use a second potentially effective $W$ cue; order.

A third potential cue--horizontal displacement--was also observed by Hershberger and Urban (1970b). An $\underline{0}$ viewing a figure approaching maximum $W$ in $C W$ rotation may note that as the area to the right of the axis increases the left side decreases in $W$, such that the whole figure is seen as shifting right. In CCW, the figure periodically shifts left. Thus, an $\underline{0}$ may determine rotation direction by observing the direction of the periodically congruent shift in the horizontal orientation of the target.

Contrary to Day and Power, the above geometrical analysis shows that an $\underline{O}$ may use any or all of three potentially effective cues to ascertain the true directions: (a) the relative periods or rate of $\mathrm{W}$; (b) the order in which maximum $W$ is attained; and, (c) the direction of displacement in orientation. Each of these cues represents an asymmetry of change for the two directions of motion. These asymmetries depend upon the visual angle subtended by the circle in Figure 1. The larger the visual angle, the greater the asymmetry. Consequently, the basic premise of Day and Power is not geometrically valid. However, in order to demonstrate that their theory is psychophysically invalid, it must be demonstrated that $\underline{\text { Os }}$ can use these cues.

Psychophysical tests of these cues are available. Bronstein (1966) and Gibson and Cibson (1957) have demonstrated that $\underline{0}$ siewing rigid objects with polar projection from a two dimensional target could, 
in fact, determine the direction of rotation. It was not clear, however, whether the veridical perception was mediated by the proximal transformations in $\mathrm{H}$, W, or both. Hershberger (1967), therefore, used a one

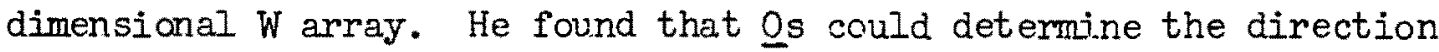
provided the projection was markedly polar. Since the principal parameter was the degree of polarity, Hershberger and Urban (1970a) tested projection distance. Their results showed that the limiting visual angle below which $W$ cues are not effective is about $\theta=14.3^{\circ}$.

Jansson and Borjesson (1969) using an oscilliscope to generate moving figures reported contradictory results. They found that $\underline{O}$ viewing rotating figures which varied as a function of polar $W$ trarsformations and parallel $\mathrm{H}$ transformations could not determine the direction of rotation. It might be suspected, however, that their apparatus was at fault since cues of proximally constant size and brightness indicated no change in distance from $\underline{\mathrm{S}}$.

Finally, Hershberger and Urban (1970a) tested three cues of the W transformation; horizontal displacement, order and relative rate. They found that $\underline{\underline{O}}$ were able to identify the direction of rotation using each of the three motion parallax cues with increasing accuracy resulting from increasingly numerous cues. In a follow-up study, Hershberger and Carpender (1971) found the three cues to be the sufficient mediators of veridical judgments. Therefore, the Day and Power theory is both geometrically and psychophysically invalid for W transformations in polar projection.

The discussion so far has dealt with the $W$ dimension of the projected array. Jansson and Borjesson (1968) in a detailed analysis of differential angular velocity observed that in parallel projection 
H transformations provide equivocal information. In polar projection, however, $H$ transformations provide non-ambiguous information. That is, since the retinal $\mathrm{H}$ increases with approach and decreases with recession, there is an asymmetry of change for the two directions. In CW rotation, $H$ increases to the right of the axis and decreases to the left. In CCW this relation is reversed. Thus, $H$ transformations provide a potentially effective cue to rotation direction.

An $Q$ may further utilize the $H$ transformations by comparing the relative size of the vertical sides (i.e., H-H). This may be done by discriminating any difference in the $\mathrm{H}$ of the ends, or by obserring the slant of the connecting horizontal sides. If points to the right of the axis converge as points to the left diverge, then CCW rotation is occuring. If this relation is reversed, CW rotation is occuring. Although this potential cue is similar to the single $H$ transformation, there is a difference. The area in which each cue is most effective is not the same.

Examine, for example, the parallel projections from the circular path in Figure 3. The distance traveled by the target from $A$ to $B$ equals $B$ to $C$. Yet the distance traveled from the $\underline{O}$ is mach greater from $C^{\prime \prime}$ to $B^{\prime \prime}$ than from $B^{\prime \prime}$ to $A^{\prime \prime}$. Since the time to travel $A B$ equals $B C$, the rate of change from $A^{\prime \prime}$ to $B^{\prime \prime}$ is greater than from $B^{\prime \prime}$ to $C^{\prime \prime}$. This means that most of the $H$ transformation occurs in the vicinity of frontoparallel. On the other hand, when a two-sided target is in the vicinity of frontoparallel the difference in the $\mathrm{H}$ of the ends is least. Most $\mathrm{H}-\mathrm{H}$ occurs as the target traveis from $\mathrm{A}$ to $\mathrm{B}$ in the vicinity of sagittal. Thus, an $\underline{0}$ may employ two kinds of potentially effective 


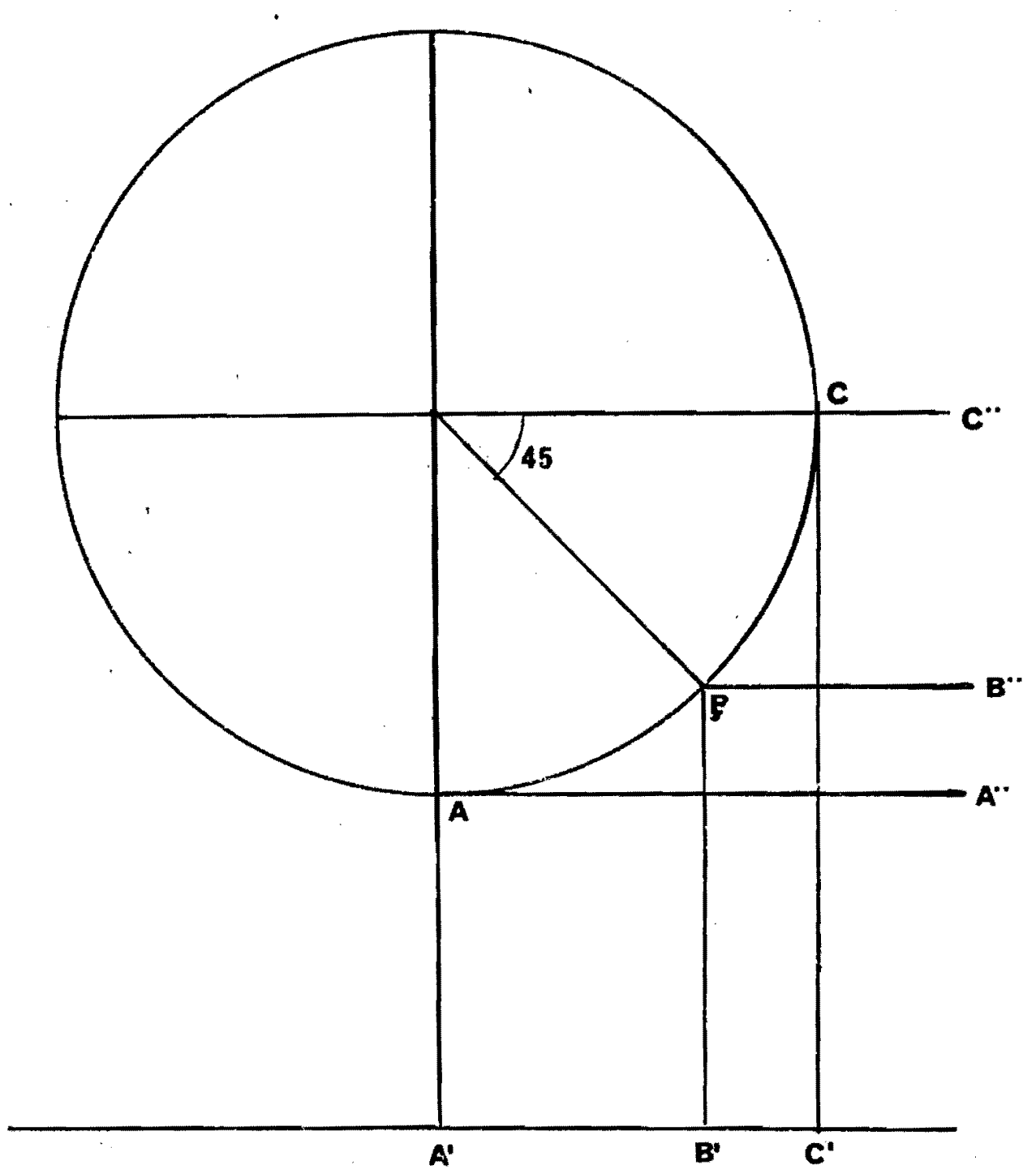

Figure 3. Parallel projections from the circular path (see iext) 
cues in the vertical dimension; (a) the increase or decrease of $\mathrm{H}$ per side, or (b) the convergence or divergence of a figure. It still must be demonstrated than an $\underline{0}$ can vse these cues.

Janssen and Barjesson (1968) tested the $\mathrm{H}$ transformations and found that $\underline{O}$ can use the cue information for a one-sided figure. This indicates that an $\underline{0}$ can use the relative rate of increase or decrease in $H$ per side as a cue. In another experiment, Jansson and Barjesson tested the effect of two vertical lines in a polar projection (H-H).

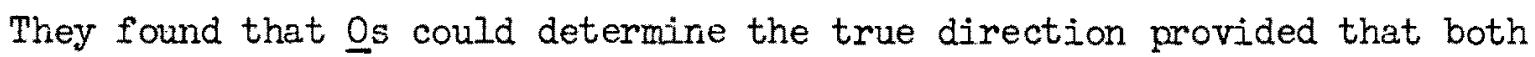
lines were changing horizontally. This indicates the importance of the relative convergence and divergence of a figure.

The work of Power (1967) and Murch (1970) indicates that the "see-saw" motion of the connecting horizontal sides is the most important cue toward reducing apparent reversals. Since this "see-saw" motion varies as a function of $\mathrm{H}-\mathrm{H}$, the empirical demonstration by Jansson and Barjesson that an $\underline{0}$ can use the transformations of two vertical sides $(\mathrm{H}-\mathrm{H})$ to determine true direction supports the conclusions of Power (1967) and Murch (1970). The fact that the thresholds for the horizontal plane are lower than the vertical plane (Graham, 1963) could explain why the "see-saw" motion was found to be the most significant cue. In general, this means that Qs tend to use $\mathrm{H}$ transformations over W transformations. A model which accounts for the oscillation phenomenon could be based on this dominance of "see-saw" transformetions.

All of the research previously cited deals specifically with rotating targets. Robert Zenhausern (1968), on the other hard, believes he has discovered a "new visual illusion: the perception of rotation under conditions of oscillation." In his experinents he has found that 
the oscillation of a trapezoid with the smell end in front may appear to rotate. This effect was subsequently compared to the original version of the illusion by Zenhausern (1969).

The results of his comparison show that the "new" illusion was similar to the older version with respect to the distance from the $\underline{0}$. Perspective, however, was said to have a differential effect upon the two illusions. Increases in the perspective--the difference in the length of the vertical sides, $\mathrm{H}-\mathrm{H}-$-increases the illusion of oscillation with rotating targets, whereas it decreases the illusion of rotation with oscillating targets. If we consider these phenomena as two manifestations of the same illusion, these results mean that increases in $\mathrm{H}-\mathrm{H}$ result in increases in the perception of oscillation and decreases in $\mathrm{H}-\mathrm{H}$ result in an increase in the perception of rotation. It appears as though the new illusion is governed by the same stimuli as the older version. A model for the illusion should be able to account for the new phenomenon.

\section{AN ALTERNATIVE MODEL}

In this section a new explanation is presented which can account for the frequency of $A R$ and the RAR in both oscillating and rotating targets. Furthermore, it is argued that this model can account for the perception of rotary motion.

It seems well agreed that a three dimensional figure rotating in depth is represented on the retinal plane in terms of two dimensional exparsions and contractions. These expansions and contractions convey equivocal information in parallel projection. In polar projection, however, true directional information is conveyed (Hershberger, 1967; 
Jannson and Borjesson, 1969; Mackae and Power, 1970).

The directional information is primarily provided by the variations in retinal $H$. This is probably because the variations in retinal $W$ are effective only when the projection is markedly polar (Hershberger, 1967).

Since directional information can account for the true perception, the lack of it can account for ARs. That is to say, the greater the perceptability of veridical motion cues, the less the probability of illusion. Therefore, the frequency of ARs can be explained in terms of the salience of rotary motion cues. Consider a rotating square. It has been demonstrated that the "see-saw" motion of the horizontal sides $(\mathrm{H}-\mathrm{H})$ is the most important cue toward determining the true direction of rotation (Murch, 1970; Power, 1967). That is, the cue provided by the relative convergence and divergence of the horizontal sides decreases the number of AR.

Decreases in AR associated with increases in the physical $W$ of a rectangular figure may be explained as the result of the over-emphasis of the "see-saw" cue. In other words, distally the increased distance between the vertical sides increases their proximal disparity $(\mathrm{H}-\mathrm{H})$. Thus, the true rotation direction is easier to determine.

Increases in AR associated with increases in the physical $\mathrm{H}$ may be explained as a de-emphasis of the "see-saw" cue. That is, whereas the size of the figure increases, the distance between the vertical sides remain the same. Thus, the ratio of the amount of "see-saw" motion to the overall size of the figure is less.

A figure such as a trapezoid, with a physical slant in the horizontal sides, constitutes misleading slant or "see-saw" information. That is, the constant difference in $\mathrm{H}-\mathrm{H}$ perceived with rotating trapezoids 
and the apparent difference with oscillating rectangles is equivocal. Thus, many ARs are reported with rotating trapezoids. Conversely, when a trapezoid is oscillated with the small end in front, the apparent difference in $\mathrm{H}-\mathrm{H}$ corresponds to a rotating square. Consequently, few ARs are reported with trapezoids oscillating with the small end in front. The oscillation of a trapezoid with the large end in front consists of strong emphasis of the "see-saw" cue; that is, proximally the difference in the length of the near and far side is enhanced. The principle is: the perception of rotation varies with the acuity of true or misleading "see-saw" information.

An explanation of the RAR may also be expressed in terms of the change in the retinal image. Consider a figure as it rotates in depth. The amount of retinal change in $W$ decreases to zero as the figure approaches frontoparallel. At the same time, the difference in the $\mathrm{H}$ of the vertical sides $(\mathrm{H}-\mathrm{H})$ decleases as both approach the same plane. At some point near, but before frontoparallel, the amount of $\mathrm{W}$ and $\mathrm{H}-\mathrm{H}$ variation must fall below threshold. In addition, this threshold increases, i.e., point occurs earlier, as speed and distance of the moving target increase or as the physical W increases (Zegers, 1948). ConsequentIy, the RAR-the end points of the angular traverse--occur at the point where the combined thresholds of horizontal (W) and vertical (H-H) movement occur. Presumably this would occur near the threshold for $\mathrm{W}$ since only motion information is conveyed by the $\mathrm{H}-\mathrm{H}$ variation. The present explanation is primarily based upon the hypothesis that the apparent motion is dependent ucon the acuity of true or misleading "see-saw" (H-H) information. However, there is no empirical. evidence to suggest that the transforations in $\mathrm{H}-\mathrm{H}$ are dominant over $\mathrm{H}$ 
transformations in the amount of information conveyed. Therefore, the present study will seek to clarify the role of the H-H transformations.

\section{HYPOTHESIS TEST}

The alternative explanation for ARs relies heavily upon the $\mathrm{H}-\mathrm{H}$ transformations as the dominant cue to true rotation direction. These $\mathrm{H}-\mathrm{H}$ transformations are most effective in the vicinity of the sagittal plane (see page 8). Transformations in H, on the other hand, are most effective in the area of the frontoparallel plane. Since there is this difference in the areas of greatest effectiveness, it is possible to divide orthogonally the two cues into separate visual projections. Moreover, by maintaining sufficient distance, these projections are not confounded by $W$ cues.

According to the present explanation, $\underline{0}$ s viewing a projection which showed a rotating figure as it passed from $45^{\circ}$ before to $45^{\circ}$ after the sagittal plane $(\mathrm{H}-\mathrm{H})$ should determine the true rotation direction more often than Os viewing a projection from $45^{\circ}$ before to $45^{\circ}$ after the frontoparallel plane ( $\mathrm{H}$ cue). In terms of the whole circular path--both projections together--a confirmation of this hypothesis means that $\mathrm{H}-\mathrm{H}$ transformations convey more directional information than transformations in $\mathrm{H}$. 
METHOD

\section{SUBJECTS}

Sixteen university students enrolied in introductory psychology classes earned bonus points as $\underline{0}$.

\section{APPARATUS}

A single $10 \times 15$ inch target, (see Figure 4) was constructed of I/8 inch thick aluminum. In order to isolate the figural transformations, the target was painted with Nite Brite Iuminous paint.

The target was rotated on the vertical shaft of a D.C. motor at 10 RPM. The experimenter (E) was able to arbitrarily set the rotation direction without the knowledge of $\underline{0}$. Four micro-switches were located on the housing of the motor shaft. When tripped by a flange on the shaft, the switches relayed a pulse to a Prontor-Press electric camera shutter. The shutter served as an eye-piece which allowed either eye, but not both simultaneously, to view the target. E could set the shutier to automatically occlude the target as it rotated through sagittal from $45^{\circ}$ to $135^{\circ}$ and from $225^{\circ}$ to $315^{\circ}$ or through frontoparallel from $135^{\circ}$ to $225^{\circ}$ and from $315^{\circ}$ to $45^{\circ}$. In order to prevent the apparatus from providing additional cues, the $\underline{O}$ heard a white noise with headphones. The projection-time was controlled by a Gra-Lab timer. During each projection the $\mathrm{O}$ recorded which direction he was apparently seeing the figure rotate on one of two key switches. Each key was attached to a 60 second Lafayette electric timer. 


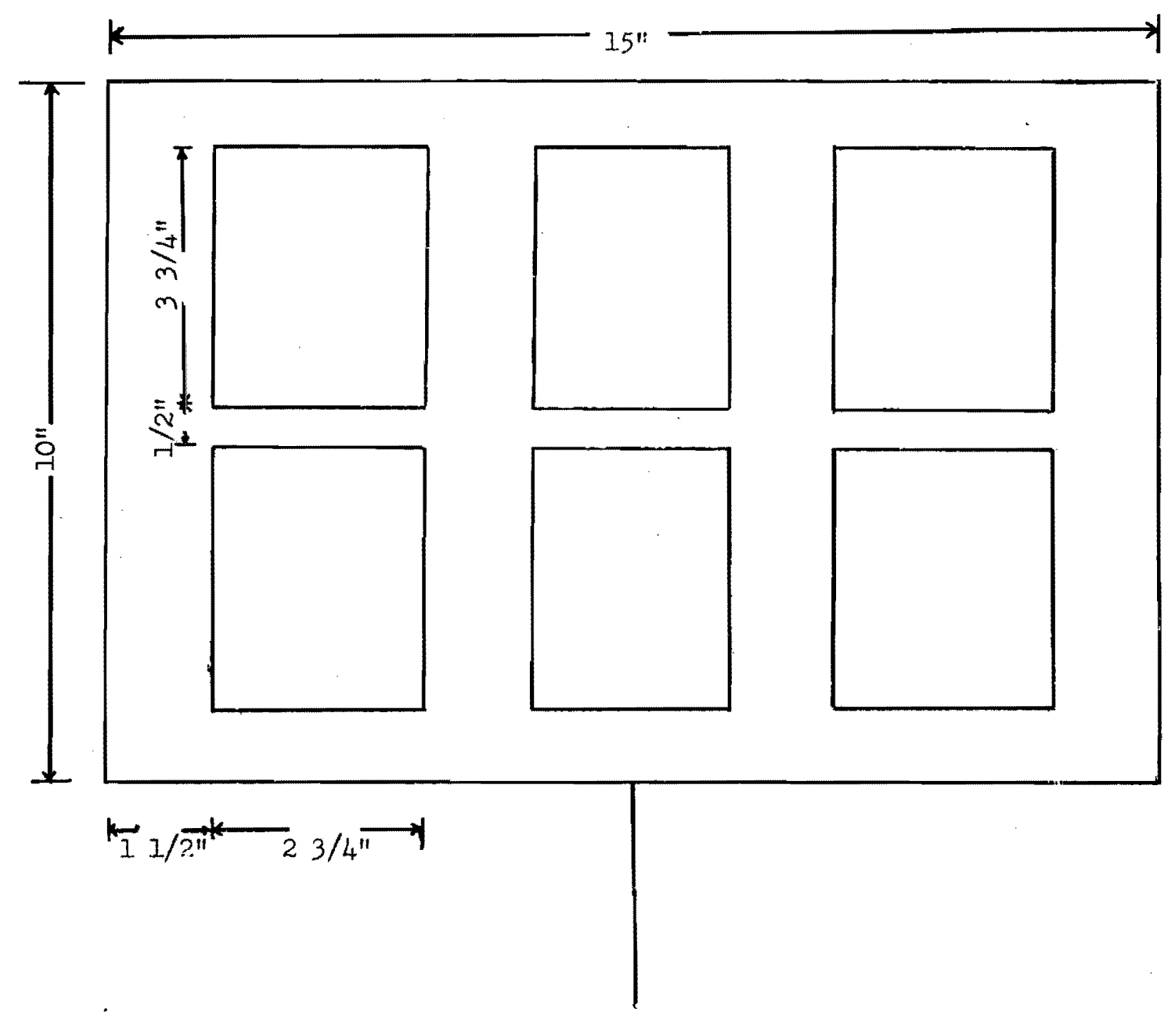

Figure 4: Dimensions of the target. 
III. PROCEDURE

The $\underline{\text { ss }}$ were randomly assigned to two equal-sized, independent groups. Group I saw the target about its sagittal plane. Group II saw the target about its frontoparallel plane. Upon arrival $\underline{\text { s }}$ were instructed that they would be viewing a target which might either rotate or oscillate, and that they were to record the apparent direction of rotation by depressing the right key for $\mathrm{C}$ and the left key for CC rotation. They were then seated at a table $1 / 4$ feet from the target, beyond W threshold (Hershberger, 1970). Qs donned lightproof goggles for dark adaptation. Meanwhile the $\underline{E}$ charged the figure with a 100 watt bulb at a distance of one foot. After two minutes, the laboratory was darkened and the $\underline{\underline{O}}$ removed the goggles and donned headphones. Then the $\underline{E}$ asked the $\underline{O}$ if he could clearly identify the target. When the $\underline{O}$ indicated that he could, the white noise came on and the experiment began. Each group saw eight, 40 second projections, four CW and four $\mathrm{CCW}$, in the order $\mathrm{C}, \mathrm{CC}, \mathrm{CC}, \mathrm{C}, \mathrm{CC}, \mathrm{C}, \mathrm{C}, \mathrm{CC}$. 
RFSUITS

In Table I, the means and standard deviations for the number of seconds of correct and incorrect directional judgments are given. The null hypothesis that the mean number of seconds of veridical perception were equal for the two groups was rejected, $(t=2.27, p<05)$. Thus, the sagittal group accurately judged the rotation direction more often than the frontoparallel group. A test of the total number of seconds in which directional judgments were made by each of the two groups was found to be nonsignificart, $(t=3.21, p>.05)$. Both groups displayed an approximately equal number of directional judgments. 


\section{TABLE I}

MEANS AND STANDARD DEVIATIONS OF NIMBER

CORRECT AND TOTAL NUMBER OF SECONDS

IN DIRECTIONAL JUDCMENTS

\begin{tabular}{|l|l|c||c|c|}
\hline \multirow{2}{*}{ Judgment } & \multicolumn{4}{|c|}{ Groups } \\
\cline { 2 - 5 } & \multicolumn{3}{|c|}{ Sagittal } & \multicolumn{2}{c|}{ Frontopara.11e] } \\
\cline { 2 - 5 } & Mean & SD & Mean & SD \\
\hline Correct & 38.43 & 11.64 & 28.43 & 12.60 \\
\hline \multirow{2}{*}{ Total } & 46.52 & & & \\
\hline
\end{tabular}




\section{DISCUSSION}

The results were quite straightforward, and showed that projections of rotations through the sagittal plane convey directional information more effectively than projections from frontoparallel. Furthermore, since the instructions specifically discouraged guessing, the larger mean veridical judgments displayed by the sagittal group may indicate greater confidence on the part of $\underline{Q} s$.

Day and Power (1965) postulate that the RAR varies as a consequence of the AR. That is, the endpoints of the angular traverse occur as a consequence of the change in orientation of the target as it reverses direction. However, since it is apparent that the frequency of AR is not governed by chance factors, it would seem that the RAR is not governed by chance factors. The present explanation offers a psychophysical basis for the RAR which is consistent with prior research on such variables as distance, speed, etc. The RAR is a covariate of AR, neither consequential nor causal.

The consistency with which the "new model" describes the trapezoid illusion is related to the specificity of stimuli in the environment. Older explanations have dealt with assumptions on the part of the $\underline{\underline{O}}$ or ambiguity on the part of the stimuli. Neither type of generality in the older theories can predict all of the diverse and complex perceptions associated with Ames trapezoid illusion. 


\section{REFERENCES}

Ames, A. Visual perception and the rotating trapezoidal window. Psychological Monographs, 1951, 65 (C7, Whole No. 324).

Branstein, M. I. Sensitivity of the observer to transformations of the visual field. Jourmal of Experimental Psychology, 1966, 72, 683690.

Burham, C. A., \& Ono, H. Variables altering the perception of the rotating trapezoidal illusion. American Journal of Psychology, $1969,82,86-98$.

Canestrari, R. Ossenazioni sul senomeno del trapezic routante. Rivista de Psicologia, 1956, 50, 1-20.

Cross, J. F. Linear perspective as a cue in misperceived rotary motion. Perception and Psychophysics, 1969, 6(3), 145-146.

Day, R. H., \& Power, R. P. Apparent reversal (oscillation) of rotary motion in depth: An investigation and general theory. Psychological Review, 1965, 72, 117-127.

Epstein, W., Jansson, G., \& Johannson, G. Perceived angle of oscillatory motion. Perception and Psychophysics, 1968, 3, 12-16.

Freeman, R. B., \& Pasnak, R. Perspective determinals of the rotary trapezoid illusion. Journal of Experimental Psychology, 1968, 76, 94-101.

Gibson, J. J., \& Gibson, E. J. Continuous perspective transformations and the perception of rigid motion. Journal of Experimental Psychology, 1957, 54(2), 129-139.

Graham, C. H. On some aspects of real and apparent visual movement. Journal of the Optical Society of America, 1963, 53, 119-125.

Hershberger, W. A. Comment on apparent reversal (oscillation) of rotary motion in depth. Psychological Review, 1967, 74, 235-238.

Hershberger, W., \& Urban, P. Depth perception from motion parallax in one directional polar projections: Projection versus viewing distance, Journal of Experimental Psychology, 1970, 86, 152164. (a)

Hershberger, W. A., \& Jrban, D. Three motion parallax cues in one directional polar projection of rotation in depth. Journal of Experimental Psychology, 1970, 86, 380-384. (b) 
Jannson, G., \& Borjesson, E. Perceived direction of rotary motion. Perception and Psychophysics, 1969, 6, 16-26.

Mackae, K. D., \& Power, R. P. Critical comment on one aspect of Graham's "On real and apparent movement." Journal of the Optical Society of America, 1969, 59, 1002.

Mullholland, T. B. Motion perceived while viewing rotating stimulus objects. American Journal of Psychology, 1956, 69, 96-100.

Murch, G. M. The perception of rotary motion. Joumal of Experimental Psychology, 1970, 86, 83-85.

Pastore, N. Some remorles on Ames oscillatory effect. Psychological Review, 1952, 59, 319-323.

Power, R. P. Stimulus properties which reduce apparent reversal of rotating rectangular shapes. Journal of Experimental Psychology, 1967, 73, 595-598.

Zegers, R. T. Monocular movement parallox thresholds as a function of field size, field position, and speed of stimulus movement. Journal of Psychology, 1948, 26, 377-380.

Zenhausern, $R$. The perception of rotation with an oscillating trapezoid. Psychonomic Science, 1968, 13(2), 79-80.

Zenhausern, R. The effects of perspective on two trapezoid illusions. Perception and Motor Skills, 1969, 28, 1003-1009. 


\section{APPENDIX}




\section{ABBREVIATIONS}

AR . . apparent reversal

CCW . . . counter clockwise

$\mathrm{CW} . .$. clockwise

E . . . experimenter

$\mathrm{H}-\mathrm{H}$. . . a difference in height

H.... height

0.... observer

RAR . . . range of apparent reversals

SD . . standard deviation

W. . . width

$\theta$. . . visual angle 